IZA DP No. 4302

Expected Inflation, Sunspots Equilibria and Persistent Unemployment Fluctuations

Frédéric Dufourt

Teresa Lloyd-Braga

Leonor Modesto

July 2009 


\title{
Expected Inflation, Sunspots Equilibria and Persistent Unemployment Fluctuations
}

\author{
Frédéric Dufourt \\ BETA, Université de Strasbourg \\ Teresa Lloyd-Braga \\ Universidade Católica Portuguesa (UCP-FCEE) \\ Leonor Modesto \\ Universidade Católica Portuguesa (UCP-FCEE) \\ and IZA
}

Discussion Paper No. 4302
July 2009

IZA

P.O. Box 7240

53072 Bonn

Germany

Phone: +49-228-3894-0

Fax: +49-228-3894-180

E-mail: iza@iza.org

\begin{abstract}
Any opinions expressed here are those of the author(s) and not those of IZA. Research published in this series may include views on policy, but the institute itself takes no institutional policy positions.

The Institute for the Study of Labor (IZA) in Bonn is a local and virtual international research center and a place of communication between science, politics and business. IZA is an independent nonprofit organization supported by Deutsche Post Foundation. The center is associated with the University of Bonn and offers a stimulating research environment through its international network, workshops and conferences, data service, project support, research visits and doctoral program. IZA engages in (i) original and internationally competitive research in all fields of labor economics, (ii) development of policy concepts, and (iii) dissemination of research results and concepts to the interested public.
\end{abstract}

IZA Discussion Papers often represent preliminary work and are circulated to encourage discussion. Citation of such a paper should account for its provisional character. A revised version may be available directly from the author. 
IZA Discussion Paper No. 4302

July 2009

\section{ABSTRACT \\ Expected Inflation, Sunspots Equilibria and Persistent Unemployment Fluctuations*}

We propose and estimate a model where unemployment fluctuations result from self-fulfilling changes in expected inflation (sunspot shocks) affecting nominal wage bargaining. Since the estimated parameters fall near the locus of Hopf bifurcations, country-specific expected inflation shocks can replicate the strong persistence and heterogeneity observed in European unemployment rates. They also generate positive comovements in macroeconomic variables and a large relative volatility of consumption. All these features, hardly accounted for by standard sunspot-driven models, are explained here by the fact that liquidity constrained workers, facing earnings uncertainty in the context of imperfect unemployment insurance, choose to consume their current income.

JEL Classification: J60, E32, E37

Keywords: unemployment fluctuations, sunspots equilibria, expected inflation, wage bargaining

Corresponding author:

Frédéric Dufourt

Bureau d'Economie Théorique et Appliquée

CNRS UMR 7522

Université de Strasbourg

61 Avenue de la Forêt Noire

F-67085 Strasbourg

France.

E-mail: dufourt@unistra.fr 


\section{Introduction}

The evolution of European unemployment since the beginning of the 1980s remains puzzling for many economists. First, as documented below, it is characterized by a very large heterogeneity across countries, even for countries that are geographically close or face similar economic conditions. Second, in all these countries, unemployment fluctuations are very persistent.

To account for these two features, the literature typically emphasizes the interactions between labor market institutions and the process of jobs creation and destruction and flows in and out employment using the canonical matching model of Mortensen and Pissarides (1994). Following Merz (1995), Andolfatto (1996) and Den Haan et al. (2000), the recent generation of Dynamic Stochastic General Equilibrium (DSGE) models with imperfect matching illustrated how such non-competitive features in the labor market, taken alone or in interaction with other market imperfections such as wage rigidity (Hall, 2005), could greatly increase the persistence in unemployment fluctuations in response to standard productivity shocks.

In spite of considerable progress, these theories still have difficulties in explaining the large heterogeneity of unemployment series across European countries. As Blanchard (2006) emphasizes, differences in labor market institutions are important but provide only a partial answer to this question, because heterogeneity is also strong across countries often considered similar with respect to such institutions. In addition, the geographical proximity and homogenous economic environment make it difficult to believe that European countries face drastically different technological conditions at any point in time. Hence, the reliance on technological shocks as the predominant source of impulsion in DSGE models with unemployment is hard to reconcile with this large observed heterogeneity.

The aim of this paper is to provide an alternative, mostly complementary explanation for both the strong persistence and the large cross-country heterogeneity in European unemployment rates. Following the long-lasting tradition initiated by the seminal contribution of Phelps $(1967,1968)$ and Friedman (1968), which structured the empirical and theoretical debates around the "expectations-augmented Phillips curve", and the insights of the New Keynesian Phillips curve literature (Galí and Gertler, 1999), we provide a model in which changes in expected inflation are the crucial determinant of short-run 
unemployment fluctuations. In our model, which is a simplified version of the framework developed in Dufourt et al. (2005, 2008), an expected future increase in inflation affects unemployment today because workers wish to negotiate a higher nominal wage. However, in contrast to this previous literature, unemployment fluctuations do not occur because of a difference between expected and realized inflation, following for example an unexpected monetary policy shock. Rather, changes in expected inflation may occur independently of any change in economic fundamentals and be self-fulfilling. This follows the literature on endogenous fluctuations and "sunspots equilibria" revived in the eighties by the leading contributions of Shell (1977), Azariadis (1981), Grandmont (1985) and others. ${ }^{1}$ Since, as documented below, expectations of future inflation are very heterogenous across countries but are strongly negatively correlated with domestic cyclical unemployment, they are a natural candidate to account for the observed persistence and heterogeneity in cyclical unemployment rates. Indeed, our analysis of French data reveals that the cyclical unemployment rate is much more strongly negatively correlated with expected inflation changes than with the actual inflation rate. The model is consistent with this empirical observation, as an expected increase in future inflation leads to a decrease in current unemployment, once general equilibrium effects are taken into account.

We then proceed with an empirical assessment of the model. First, the main parameters are estimated using a Simulated Method of Moments and minimum distance criterion. More precisely, the model parameters are estimated to match as closely as possible the empirical autocorrelation function of the cyclical unemployment rate of France. The model proves to be very successful in this dimension. We can explain this large endogenous persistence with white-noise expected inflation shocks by the fact that the estimated parameters are located near the locus where Hopf bifurcations occur in the parameters space. ${ }^{2}$ The model is also able to replicate some features considered hard to be accounted for by available Real Business Cycles and endogenous fluctuations models. In particular, it replicates the autocorrelation function of output growth, in contrast to many RBC models (see Cogley and Nason, 1995), even though sunspot shocks are by definition white noise stochastic processes. The model also accounts for positive co-movements

\footnotetext{
${ }^{1}$ See also Cass and Shell (1983), Farmer and Woodford (1984, 1997), Azariadis and Guesnerie (1986) and Woodford (1986).

${ }^{2}$ This means that the two eigenvalues of the Jacobian matrix of the dynamic system come as complex conjugates with modulus close to one.
} 
of consumption, investment, output and hours worked in response to "demand" shocks without relying on increasing returns to scale or externalities. This contrasts to many sunspot-driven DSGE models (see Schmitt-Grohé, 2000), where sufficiently large increasing returns to scale are necessary for the existence of sunspot equilibria and "boom-bust" cycles generated by demand shocks, even if the combination with other features (such as variable capital utilization rate, as in Benhabib and Wen, 2004) reduces the required lower bound. Finally, it explains the large sensitivity of consumption to current output, in contrast with most DSGE models whose predictions in this dimension are typically rejected by the data. This last feature is due to the presence of financially constrained workers facing earning uncertainty in the context of imperfectly insured unemployment fluctuations.

The rest of the paper is organized as follows. In the next section we present and discuss empirical facts that motivate and validate our work. Section 3 briefly presents the model. In section 4 we obtain the equilibrium and discuss the local dynamic properties of the model. Section 5 presents the estimation procedure and discusses the results, comparing them with the related literature. Finally section 6 concludes.

\section{Some facts about unemployment fluctuations in the EU since the mid-80s}

This section describes briefly some basic facts about the evolution of European unemployment rates and their link with other relevant macroeconomic variables, in particular households' expectations about future activity and inflation. Rather than providing an exhaustive account of the specific evolution of unemployment rates in every country, ${ }^{3}$ we concentrate our analysis on a few subsets of countries, to better highlight the features more relevant for our further analysis. Specifically, we present and compare unemployment rate series for three set of countries. The first one includes three major continental EU countries, namely France, Germany and the UK, because they are geographically close and their cumulated production represents more than $50 \%$ of total GDP of EU members.

\footnotetext{
${ }^{3} \mathrm{~A}$ very detailed and complete description of the evolution of European unemployment, both in terms of facts and theoretical explanations, can be found in Blanchard (2006).
} 
For comparison purposes, we also included in this set the US unemployment rate. The second set of countries includes three major northern European countries, namely Denmark, Norway and Sweden, representative of the "Scandinavian model" of the labor market, characterized by high labor mobility, strong incentives to find new jobs coupled with high unemployment benefits. ${ }^{4}$ Finally, a third set of countries includes Italy, Portugal and Spain, three main southern European countries culturally and geographically close. The data set is quarterly, covers the period 1982:1-2006:4 and is taken from the OECD Monthly Economic Indicators database.

\subsection{Unemployment in Europe}

The first feature that emerges from inspection of the data (see Figure 1, charts in levels) is the absence, since the mid-eighties, of any systematic upward or downward trend in the long-run level of unemployment rates. There are, of course, significant differences across countries, as documented below, but the overall picture does no longer point to any obvious common trend. In fact, the harmonized unemployment rate for the EU15 area fluctuated around a roughly stable long-run value during this period. This contrasts strongly with the situation of the 70s when, in the aftermath of the two oil crises, with the simultaneous decline in Total Factor Productivity growth and the tightening in monetary policy of the early eighties, unemployment rates steadily increased in all European countries without exceptions.

The second striking feature is the large heterogeneity in unemployment rate series across countries. For example, while the EU15 long-run unemployment rate remained roughly stable during the period, Figure 1 shows that the German unemployment rate increased from 4.8 to 8 percent, the UK unemployment rate decreased from 9 to 5.8 percent, and France had a situation in between. Similar differences can be found by comparing national unemployment rates either across or within subsets of countries. Labor market "institutions" are often evoked to account for these contrasted experiences. However, as Blanchard (2006) emphasizes, such structural differences can only explain part of the

\footnotetext{
${ }^{4}$ We did not consider Finland because an important change in the definition of unemployment in 1989 implied a huge and mostly artificial increase in the unemployment rate in the early 90's. Instead we included Norway. Although not a member of the European Union, it is a member of the European Economic Area and its links with EU countries are very strong.
} 


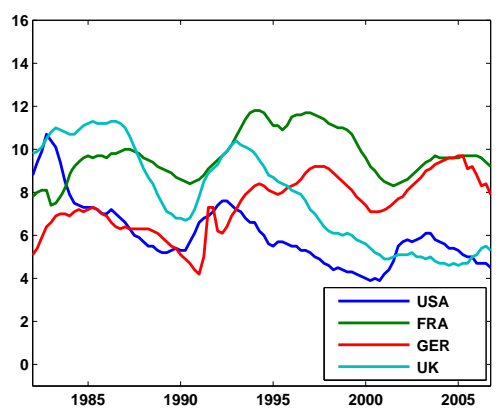

Levels

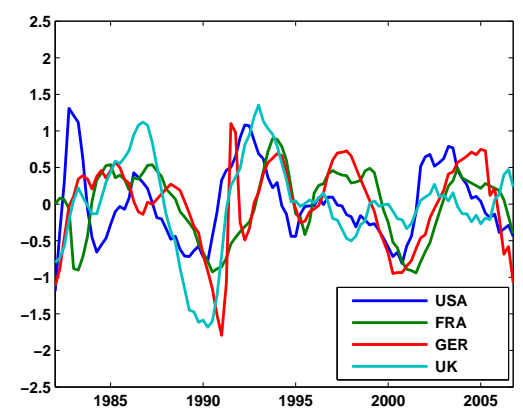

Cyclical components (HP filter)

Panel A: US and thee major continental EU countries

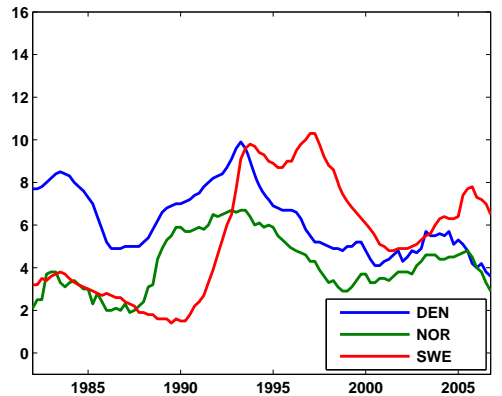

Levels

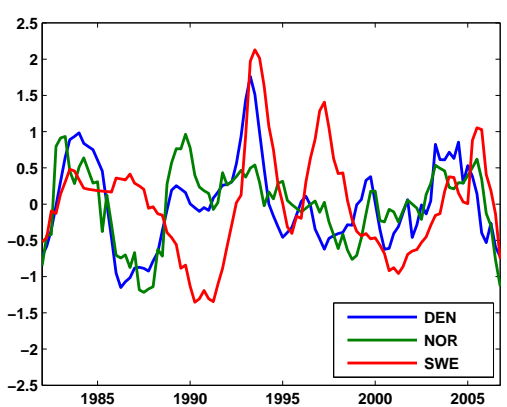

Cyclical components (HP filter)

Panel B: three northern Europe (Scandinavian) EU countries

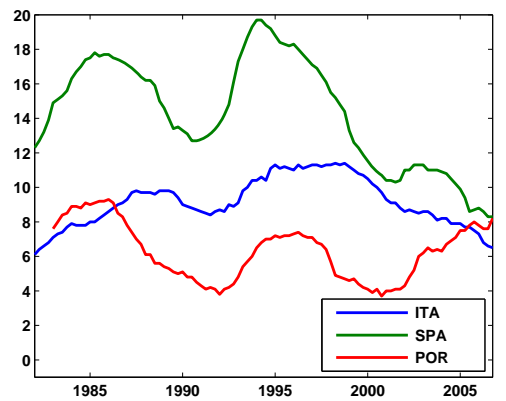

Levels

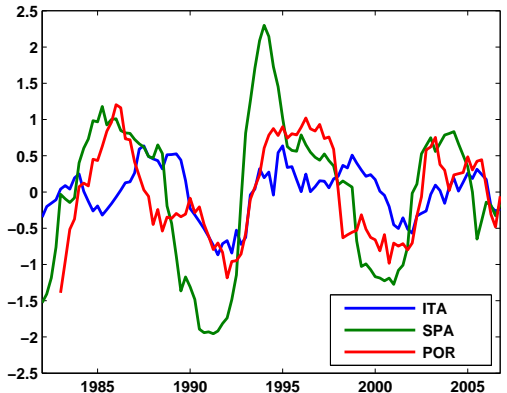

Cyclical components (HP filter)

Panel C: three southern Europe EU countries

Figure 1: Unemployment in the US and nine major European countries 
Table 1: Correlations between unemployment rates within subsets of countries

\begin{tabular}{|c|c|c|c|c|c|c|c|c|c|c|}
\hline \multirow{6}{*}{$\begin{array}{c}u \\
\text { (levels) }\end{array}$} & \multicolumn{4}{|c|}{ Cont. Eur. } & \multicolumn{3}{|c|}{ North. Eur. } & \multicolumn{3}{|c|}{ Sout. Eur. } \\
\hline & & Fra & Ger & UK & & Den & Nor & & Ita & Por \\
\hline & Fra & 1 & & & & & & & & \\
\hline & Ger & 0.54 & 1 & & Den & 1 & & Ita & 1 & \\
\hline & UK & 0.04 & -0.48 & 1 & Nor & 0.55 & 1 & Por & -0.32 & 1 \\
\hline & USA & -0.37 & -0.39 & 0.75 & Swe & -0.06 & 0.34 & Spa & 0.48 & 0.36 \\
\hline \multirow{6}{*}{$\begin{array}{c}u_{c} \\
\text { (cycl.) }\end{array}$} & \multicolumn{4}{|c|}{ Cont. Eur. } & \multicolumn{3}{|c|}{ North. Eur. } & \multicolumn{3}{|c|}{ Sout. Eur. } \\
\hline & & Fra & Ger & UK & & Den & Nor & & Ita & Por \\
\hline & Fra & 1 & & & & & & & & \\
\hline & Ger & 0.65 & 1 & & Den & 1 & & Ita & 1 & \\
\hline & UK & 0.43 & 0.34 & 1 & Nor & 0.71 & 1 & Por & 0.36 & 1 \\
\hline & USA & -0.02 & 0.27 & 0.53 & Swe & 0.26 & 0.04 & Spa & 0.44 & 0.69 \\
\hline
\end{tabular}

story. In fact, heterogeneity is also strong across countries often considered similar in terms of labor market institutions (see for example unemployment rates in Sweden and Norway in Panel B, or unemployment in Portugal and Spain in Panel C, which experienced drastically different long-run unemployment rates).

Furthermore, the cross-country heterogeneity is not only strong in terms of levels, but also in terms of cyclical components. To illustrate this, we used the HP filter to remove low frequency components in unemployment rate series. Admittedly, differences in natural rates of unemployment, reflecting structural differences in labor market institutions, should mostly appear at low frequencies and be removed by the HP filter. The left charts in Figure 1 plot the cyclical components of unemployment rates thus obtained. They show that, except for specific periods of time for which common shocks are clearly identified (for example, the cyclical increase in unemployment rates that occurred in many European countries during the recessions of the early 1990s and the early 2000s), the series exhibit very little common fluctuations, even across subsets of countries. This can also be observed in Table 1, which reports cross-correlations (for both the levels and cyclical components) of national unemployment rates for each subset of countries. The contemporaneous correlations across countries are slightly larger for cyclical components than for levels but are in many cases rather small. 


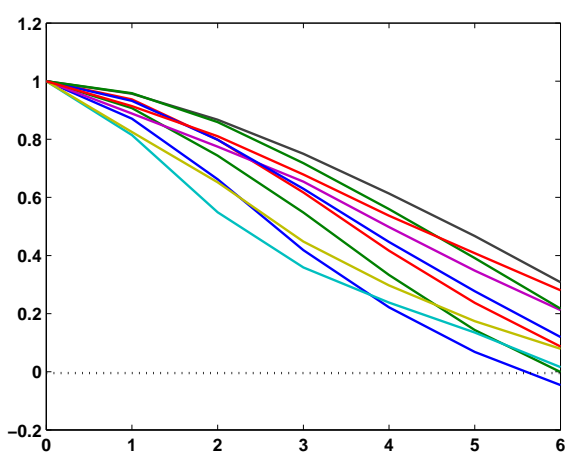

Figure 2: Autocorrelation functions of cyclical unemployment series

Hence, heterogeneity is the rule rather than the exception for both the levels and the cyclical components of European unemployment rates. In spite of this heterogeneity, there is however a third important feature which is worthwhile to emphasize, because it is common to all the countries considered. This common feature is unemployment persistence. To illustrate this, Figure 2 displays the first six lags of the autocorrelation function $(\mathrm{ACF})$ of the cyclical unemployment rates of all countries. Not only does it appear that all series display a very large amount of persistence, but the ACF functions are very similar and sometimes barely distinguishable from each other.

Theoretical explanations wishing to account for unemployment variations in the business cycle should be consistent with these three features. We argue that changes in expectations of future inflation may be a key mechanism. To support this claim, the next section gives further insights on the link between national unemployment rates and consumers expectations.

\subsection{Consumers expectations about future inflation and unem- ployment.}

Eurostat and the French national institute of statistics, INSEE, provide interesting data concerning households expectations about the future evolution of various economic variables, which are used in the construction of the Consumer Confidence Indicator. Among the questions asked in the monthly survey, one concerns the expected evolution of prices and another the expected evolution of unemployment for the year to come. Several inter- 


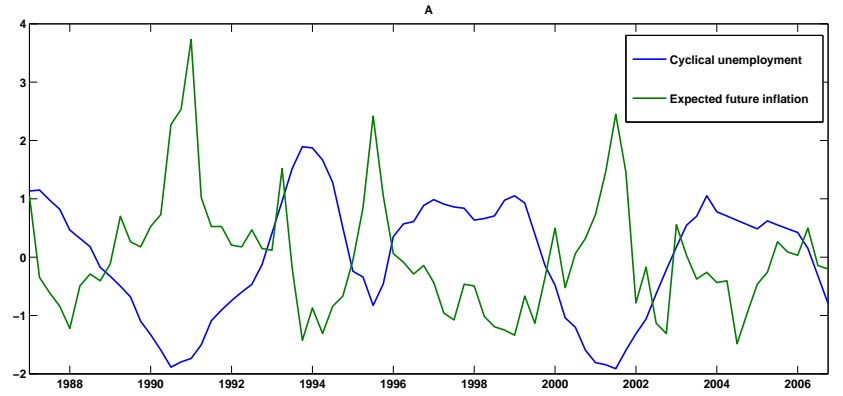

Figure 3: Expected increases in future inflation and cyclical unemployment (France, 1987-2006, standardized data)

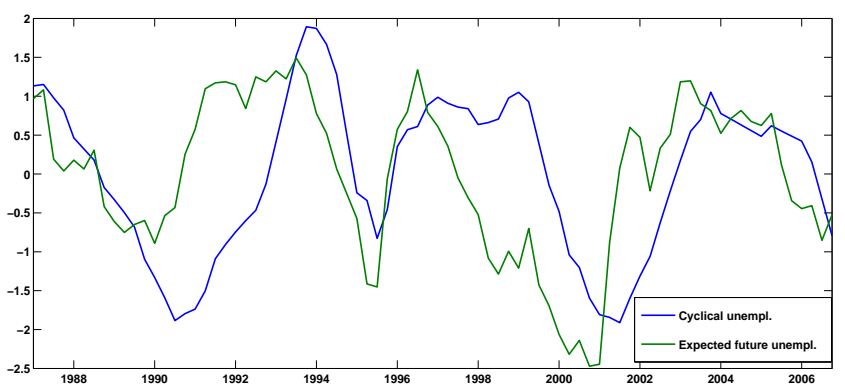

Figure 4: Expected increases in future unemployment and cyclical unemployment (France, 1987-2006, standardized data)

esting features emerge from this survey. First, as Figure 3 shows, expected future increases in inflation are strongly negatively correlated with current cyclical unemployment. This suggests that inflation expectations are a key determinant of the current unemployment rate. Table 2 reveals that the contemporaneous correlation between the Eurostat series on expected inflation and the unemployment rate is -0.66 for France. In contrast, the correlation between unemployment and current inflation is only -0.18 . Hence, changes in expected inflation are much more strongly correlated with the unemployment rate than changes in current inflation. This, together with the unemployment persistence statistics provided in the former subsection, is consistent with our conjecture that changes in expected inflation generate fluctuations in unemployment that persist for several lags.

A second interesting fact, looking at the series on expected future unemployment changes (see Figure 4), is that this series leads the series of realized cyclical unemployment. Table 2 reveals that the correlation between the two series is strongest for a gap of 4 
Table 2: unemployment fluctuations and expectations (France)

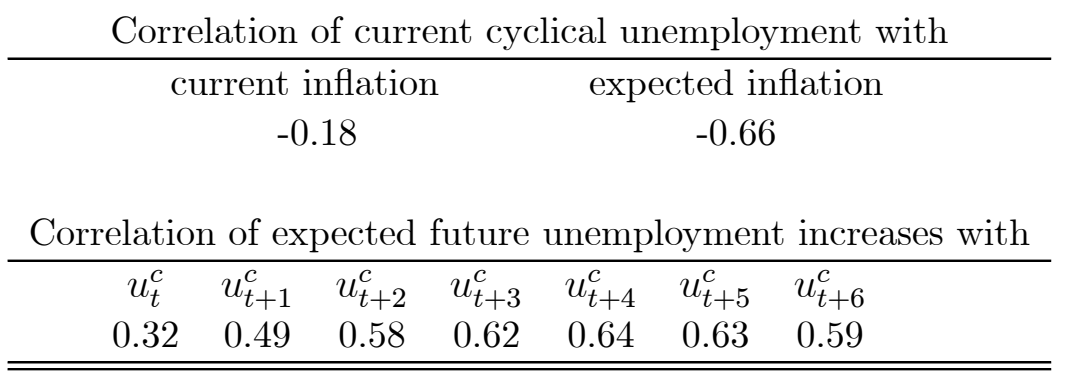

quarters. This indicates that, when households expect an increase in the unemployment rate for the year to come, they are generally right to do so because their expectations tend to be fulfilled one year later. It should also be noted that the current economic situation, as measured by the current level of unemployment, is only a poor indicator of these changes in expectations since the contemporaneous correlation between the two series is only 0.32 (see Table 2). This tends to suggest that changes in households expectations are not necessarily strongly linked with current or observable economic fundamentals.

These empirical findings are only a crude approximation of the complexity of the links existing between unemployment fluctuations and inflation, as the vast literature on the Phillips Curve or, more recently, the New Keynesian Phillips Curve illustrate. They are however consistent with some crucial predictions of the model presented below. In the model, a change in expected inflation has a direct influence on the labor market because it changes incentives (through payoff functions) of unions and firms during the bargain over the nominal wage. As a result, unemployment deviates persistently from its initial level, decreasing when an increase in inflation is expected, as shown in Section 3. Since expectations tend to be self-fulfilling, future variations in inflation and in the unemployment rate tend to validate initial expectations. This source of endogenous unemployment fluctuations due to autonomous changes in expected inflation may also explain why unemployment rates among EU countries are so heterogeneous. Table 3 reports correlations between expected inflation series in various countries with respect to France. Although data is missing for some countries, we can observe generally (and quite surprisingly) that the correlations are often very low. This remains true even after dividing the data in two sub-samples, corresponding to the periods before and after the launch of the Euro. 
Table 3: Correlations between expected inflation series in various countries with respect to France

\begin{tabular}{cccccccccc}
\hline \hline & Fra & Den & Ger & Ita & Nor & Por & Spa & Swe & UK \\
exp. infl. & 1 & 0.06 & 0.28 & 0.19 & n.a. & 0.27 & 0.54 & $0.38^{*}$ & 0.09 \\
\hline
\end{tabular}

$\left(^{*}\right) \overline{\overline{\text { Data, when available, is from } 1987 \text { to 2006. For Sweden, data start in } 1}} 996$.

\section{The Model}

We now briefly expose the theoretical model aimed to account for the empirical regularities outlined above. As this model is extensively presented and analyzed in Dufourt et al. (2005, 2008), we refer to these papers and to the Appendix for details. The basis of this model is the finance-constrained economy first proposed by Woodford (1986) and then extended by Grandmont et al. (1998) and Cazzavillan et al. (1998) to account for a more general production function. In that economy, all markets are perfectly competitive and output is produced under a constant returns to scale technology. There are two assets - money and productive capital - and two types of households: "workers" and "capitalists". A set of crucial assumptions is that workers face a borrowing constraint (they cannot borrow against future income to finance current consumption) and that capitalists, who do not work, discount the future less than workers.

The extension of Dufourt et al. (2005, 2008) consists in obtaining equilibrium unemployment in this framework, by introducing an imperfect insurance scheme provided by the government in a economy where, due to union power, wages are set above the reservation wage. The initial result of Woodford (1986) that capitalists, at equilibrium, do not hold money and save only in the form of capital continues to hold. The additional feature is that workers, facing uncertainty about their state (they can be employed or unemployed), endogenously choose not to save and to spend all their available money income in current consumption (an income which is now contingent on their past employment state). Appendix A shows that these results hold, at the steady state and in its neighborhood, if workers are sufficiently more impatient than capitalists and money is a dominated asset. ${ }^{5}$

We now proceed with a brief presentation of the main ingredients of the model. The

\footnotetext{
${ }^{5}$ Money is held by firms in order to pay nominal wages.
} 
problem solved by capitalists remains identical to that in Woodford (1986). At equilibrium, capitalists save a constant percentage of their income, i.e. $k_{t+1}=\beta R_{t} k_{t}$, where $k_{t}$ represents capital in period $t, \beta \in(0,1)$ is the discount factor of capitalists, $R_{t}=\left(r_{t}+1-\delta\right)$ is the real gross rate of return on capital, $r_{t}$ is the real rental rate of capital and $0 \leq \delta \leq 1$ is the capital depreciation rate.

Workers, on the other hand, may be employed or unemployed at any date. Employed workers in $t$ receive their (gross) nominal wage $w_{t}$ in cash at the beginning of period $t+1$, while unemployed workers in $t$ receive from the government, also at the beginning of period $t+1$, a constant real unemployment benefit $b$. Unemployment benefits are financed by collecting, in period $t+1$, the required real amount of taxes from each worker employed in $t, \tau_{t}$. This implies, normalizing the mass of workers to 1 , that the tax per employed worker in any period $t$ is determined by the relation $\tau_{t}=b\left(1-l_{t}\right) / l_{t}$, where $l_{t}$ is period $t$ employment rate. Since workers have no labor disutility, their real reservation wage at $t$ is given by $R W_{t} \equiv\left(b+\tau_{t}\right) E_{t} \pi_{t+1}$, where $E_{t}$ is a rational expectation operator representing expectations given the information set at time $t$ and $\pi_{t+1} \equiv p_{t+1} / p_{t}$ is the inflation factor.

Wages and employment are determined by unions and firms through an efficient bargaining on the distribution of the surplus over and above capital rental costs, union power being represented by the parameter $(1-\alpha) \in[0,1)$. As a result, real wages $\omega_{t}$ are set above the real reservation wage, using a markup factor $\mu\left(k_{t}, l_{t}\right) \geq 1$ that is increasing with unions' bargaining power, i.e. $\omega_{t} \equiv w_{t} / p_{t}=\mu\left(k_{t}, l_{t}\right) R W_{t}$. Equilibrium employment is determined by the equality between the real reservation wage and the marginal productivity of labor, i.e. $R W_{t}=M P L\left(k_{t}, l_{t}\right)$. In the space $\left(l_{t}, \omega_{t}\right)$, the $M P L$ curve is negatively sloped due to constant returns to scale. However, the reservation wage schedule - which is horizontal at the partial equilibrium, see Figure $5 \mathrm{a}$ - becomes negatively sloped at general equilibrium, with a constant elasticity of $-1 .^{6}$ It is easy to see from Figure $5 \mathrm{~b}$ that, when the equilibrium reservation wage schedule $(E R W)$ is steeper than the $M P L$ curve, an increase in expected inflation, shifting upwards the $E R W$ curve, implies an increase in current employment at general equilibrium. Thus, in this situation, current unemployment tends to be negatively correlated with expected future inflation, as suggested by our

\footnotetext{
${ }^{6}$ Indeed, taking the balanced-budget condition $\tau_{t}=b\left(1-l_{t}\right) / l_{t}$ into account, the reservation wage expression $(b+\tau) E_{t}\left(p_{t+1} / p_{t}\right)$ can be written as $\left(b / l_{t}\right) E_{t}\left(p_{t+1} / p_{t}\right)$, so that its elasticity with respect to $l$ is -1 .
} 


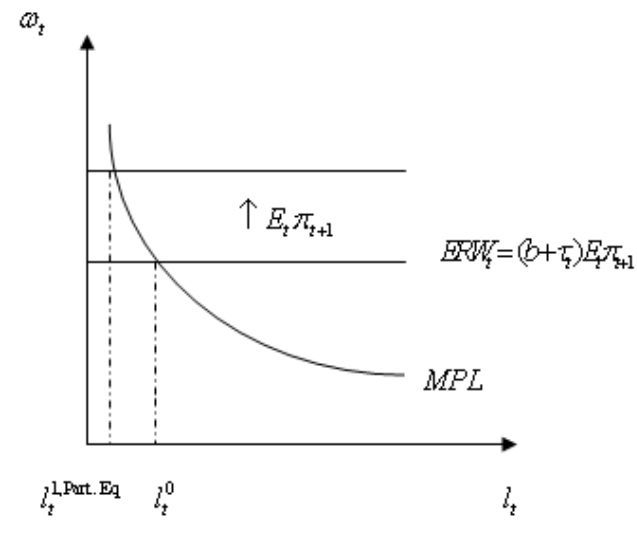

(a) partial equilibrium

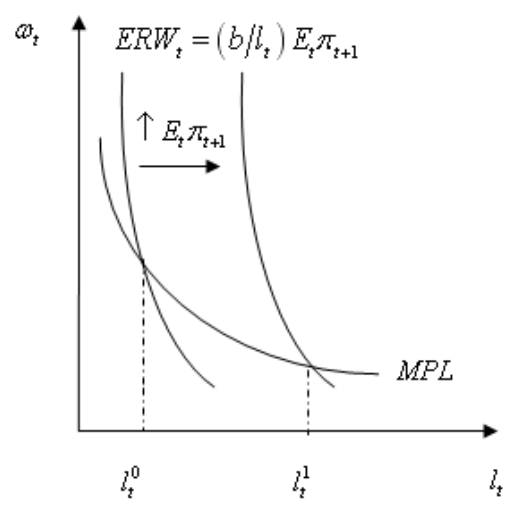

(b) general equilibrium

Figure 5: The labor market at partial and general equilibrium levels

empirical analysis (see Section 2.2).

Next, firms, anticipating the result of the bargaining process, choose the amount of capital such that $r_{t}=\alpha M P K\left(k_{t}, l_{t}\right)$, where $M P K\left(k_{t}, l_{t}\right)$ is the marginal productivity of capital. ${ }^{7}$ Inserting this last expression in the optimal decision rule of capitalists, we obtain the capital accumulation equation given by (1) below. Finally, assuming as in Woodford (1986) that money is constant over time, equilibrium in the money market requires $\omega_{t} l_{t} / \omega_{t+1} l_{t+1}=p_{t+1} / p_{t}$, since money holdings are identical to the nominal wage bill. Then, using the expressions for the real wage, the reservation wage and for the tax per employed worker, we obtain equation (2) below, the equilibrium intertemporal arbitrage condition for workers that summarizes equilibrium in the money and labor markets.

$$
\begin{gathered}
k_{t+1}=\beta\left[\alpha M P K\left(k_{t}, l_{t}\right)+(1-\delta)\right] k_{t} \\
E_{t}\left\{\mu\left(k_{t+1}, l_{t+1}\right) l_{t+1} M P L\left(k_{t+1}, l_{t+1}\right)\right\}=b \mu\left(k_{t}, l_{t}\right)
\end{gathered}
$$

Equilibrium trajectories of capital and employment are solutions of this dynamic system. ${ }^{8}$

\footnotetext{
${ }^{7}$ Due to the assumption of constant returns to scale in production, profits are zero at equilibrium.

${ }^{8}$ As explained in the Appendix a transversality condition is also required.
} 


\section{Equilibrium Dynamics}

Introducing a sequence of expectation errors $e_{t+1}$, with $E_{t}\left(e_{t+1}\right)=0$, we can write the dynamic system (1)-(2) in the following equivalent way:

$$
\begin{aligned}
k_{t+1}-v_{1}\left(k_{t}, l_{t}\right) & =0 \\
v_{3}\left(k_{t+1}, l_{t+1}\right)-v_{2}\left(k_{t}, l_{t}\right) & =e_{t+1}
\end{aligned}
$$

where $v_{1}\left(k_{t}, l_{t}\right) \equiv \beta\left[\alpha M P K\left(k_{t}, l_{t}\right)+(1-\delta)\right] k_{t}, v_{2}\left(k_{t}, l_{t}\right) \equiv b \mu\left(k_{t}, l_{t}\right)$ and $v_{3}\left(k_{t+1}, l_{t+1}\right) \equiv$ $\mu\left(k_{t+1}, l_{t+1}\right) l_{t+1} M P L\left(k_{t+1}, l_{t+1}\right)$. Defining $z_{t} \equiv\left(k_{t}, l_{t}\right)$, (3) can be written more compactly as $g\left(z_{t+1}, z_{t}\right)=\epsilon_{t+1}$, where $\epsilon_{t+1}^{\prime}=\left[\begin{array}{ll}0 & e_{t+1}\end{array}\right]$ and $E_{t} g\left(z_{t+1}, z_{t}\right)=0$. It can be verified that, under non-restrictive conditions on parameters, this dynamic system has a unique steady state equilibrium $\bar{z}$ defined by $g(\bar{z}, \bar{z})=0$, and that the Jacobian matrix of the map $z \rightarrow g(z, \bar{z})$ evaluated at $\bar{z}$ is invertible. By the Implicit Function Theorem, this system can therefore be solved for $z_{t+1}$ in the neighborhood of $\bar{z}$, leading to a solution of the form $z_{t+1}=h\left(z_{t}, \epsilon_{t+1}\right)$, i.e.,

$$
\begin{aligned}
k_{t+1} & =h_{1}\left(z_{t}\right) \\
l_{t+1} & =h_{2}\left(z_{t}, \epsilon_{t+1}\right)
\end{aligned}
$$

where $h_{1}\left(z_{t}\right) \equiv v_{1}\left(k_{t}, l_{t}\right)$ and $h_{2}\left(z_{t}, \epsilon_{t+1}\right) \equiv\left[v_{3}\left(v_{1}\left(k_{t}, l_{t}\right), .\right)\right]^{-1} \circ\left[v_{2}\left(k_{t}, l_{t}\right)+e_{t+1}\right]$.

\subsection{Types of equilibria}

From Equations (1)-(2), it is clear that $k_{t}$ is a predetermined variable whose behavior is determined by past savings decisions of capitalists. However, $l_{t}$ is a non-predetermined variable whose level is influenced by expectations, in particular with respect to future inflation. Hence, depending on the local stability properties of the steady-state, there is potentially room for stationary stochastic equilibria, close to the steady state, driven by self-fulfilling changes in expected inflation (sunspot shocks). We now briefly explain when this is the case.

When the steady state is a saddle such situations can never arise. This is because, given an initial capital stock $k_{0}$ sufficiently close to its steady state, there is a unique 
trajectory $\left\{z_{t}\right\}_{t=0,1, \ldots \infty} \equiv\left\{k_{t}, l_{t}\right\}_{t=0,1, \ldots \infty}$ defined by (4) that remains close to the steady state and therefore satisfies the transversality condition. This means that, in the absence of exogenous shocks on fundamentals, the forecast error $\epsilon_{t+1}$ is necessarily zero and there is a unique convergent path to the steady state. The dynamic model is said to be locally determinate. ${ }^{9}$

When the steady state is a sink, on the contrary, the steady-state is said to be locally indeterminate. Given the initial value of the capital stock $k_{0}$ there are now infinitely many bounded deterministic equilibrium trajectories $\left\{k_{t}, l_{t}\right\}_{t=0,1, \ldots \infty}$ converging to the steady state and satisfying the transversality condition. Also, as proved by Grandmont et al. (1998), there are also infinitely many nondegenerate stochastic equilibria driven by self-fulfilling changes on expectations (stochastic endogenous fluctuations or sunspots equilibria, $\epsilon_{t+1} \neq 0$ ), that stay arbitrarily close to the steady state. In terms of equation (4), this implies that the forecast error $\epsilon_{t+1}$ may now act as an independent source of the business cycle even in the absence of extrinsic uncertainty affecting fundamentals (see Benhabib and Farmer (1999) for further discussion).

Finally, a last but nonetheless interesting potential type of equilibria is worth discussing. It can occur when the steady state is a source and the economy is located near the point where a supercritical Hopf bifurcation occurs in the parameters space. ${ }^{10}$ In this case, as discussed in Grandmont et al. (1998), there are infinitely many stationary stochastic equilibria around an invariant closed curve that surrounds the steady state. Furthermore, there are deterministic endogenous fluctuations defined by periodic or quasi-periodic orbits, lying over the referred invariant closed curve. Thus, in this last configuration, the economy may very well exhibit infinitely recurrent unemployment fluctuations without any kind of stochastic shocks (whether on economic fundamentals or on expectations). This is a form of "hysteresis" which is relatively new compared to the

\footnotetext{
${ }^{9}$ In our two dimensional equilibrium dynamic system, a saddle is obtained when the absolute value of one local eigenvalue is higher than 1 , while the absolute value of the other is lower than 1 . A sink is obtained when the modulus of both eigenvalues are lower than 1, and a source is obtained when the modulus of both eigenvalues are higher than 1.

${ }^{10} \mathrm{~A}$ bifurcation generically occurs in nonlinear models when one or several eigenvalues of the characteristic polynomial of the system cross the unit circle through a change in some parameter. For example, a flip bifurcation occurs when one eigenvalue crosses -1 and a Hopf bifurcation occurs when two complex conjugate eigenvalues have their modulus crossing 1 . The Hopf bifurcation is said to be supercritical (resp., subcritical) when the first Lyapunov coefficient of the dynamic system is negative (resp., positive).
} 
traditional literature.

\subsection{Dynamic configurations}

In Dufourt et al. (2008), a complete analytical characterization of the local stability properties of this model was undertaken in terms of relevant parameters. Figure 6, which is easily computed as a direct application of this theoretical analysis, reports in the $(\alpha, \sigma)$ plane the bifurcation values for the elasticity of substitution between inputs in production, $\sigma$, as a function of the firms' bargaining power, $\alpha$, given an empirically based calibration for the set of other parameters described below. Two main observations can be drawn from inspection of this figure. Firstly, local indeterminacy — associated with a sink configuration - emerges for a wide range of parameters values, including the empirically relevant ones. In particular, as proved in Dufourt et al. (2008), the steady state is always indeterminate when the production function is Cobb-Douglas $(\sigma=1)$. Secondly, when the elasticity of substitution between capital and labor is different from one, both flip and Hopf bifurcations may also occur. They arise for empirically plausible values of $\sigma$ (not far away from one) as soon as unions' bargaining power is strong enough. ${ }^{11}$

In light of this analysis, it is clear that local stochastic equilibria driven by self-fulfilling changes in expected inflation (sunspots) are concrete possibilities in the model, since they occur for plausible values of the structural parameters. ${ }^{12}$ The model features as well the third type of equilibria associated to the source configuration, referred in Section 4.1. Figure 7 displays the invariant closed curve emerging when the economy is located near the point where a Hopf bifurcation occurs (in the capital-employment space). The Hopf bifurcation is found to be supercritical, implying that the invariant curve appears when the steady state is a source and that this curve is attracting.

\footnotetext{
${ }^{11}$ Remark that indeterminacy requires $\sigma>\sigma_{H}$, where $\sigma_{H}$ is the locus of Hopf bifurcations. As shown in Dufourt et al. (2008), this condition can only be met when the $E R W$ schedule is steeper than the $M P L$ curve at general equilibrium. In this case, as explained in Section 3, expected inflation and current unemployment are negatively correlated along the business cycle.

${ }^{12}$ Two recent papers, Grandmont (2008) using a Woodford model, and Nakajima (2006) using a model where workers hold capital, also introduce unemployment benefits but consider efficiency wages rather than collective bargaining. In both cases, they show that indeterminacy prevails for some values of the parameters. This suggests that indeterminacy is robust to changes in the wage setting process and that it is mostly explained by the taxation/imperfect insurance scheme. See Dufourt et al. (2008) for more discussion on this point.
} 


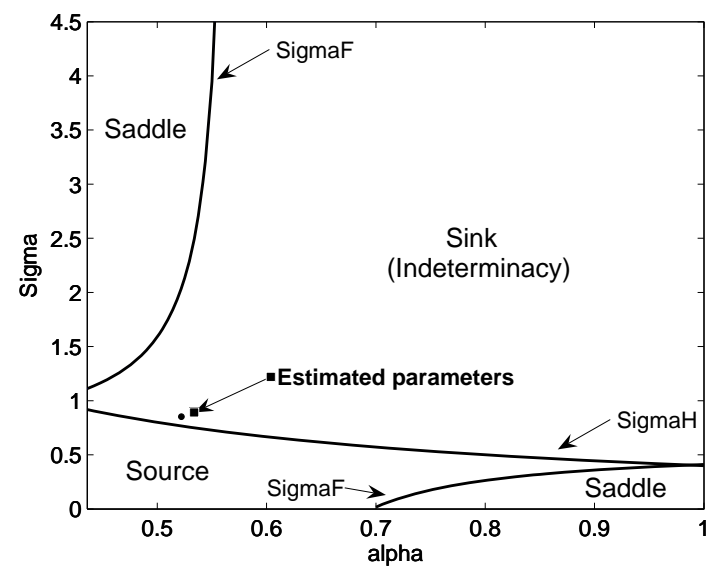

Figure 6: Local stability properties and bifurcation values (SigmaF for a flip, SigmaH for a Hopf) in the space of parameters $(\alpha, \sigma)$, for given (calibrated) values of the set of parameters $\gamma_{1}=(\beta, \delta, b, \varphi)$.

In our view, both types of equilibria would have been worth studying. However, in the context of our model, the invariant closed curve quickly disappears as parameters move away from their bifurcation value. Hence, we have chosen to concentrate our analysis on the more traditional approach pioneered by Benhabib and Farmer (1994) and Farmer and Guo (1994), consisting of generating fluctuations around the steady state due to selffulfilling changes in expectations in an economy which is locally indeterminate. The next section describes our data confrontation approach.

\section{Model evaluation}

We now investigate whether the model driven by self-fulfilling changes in expected inflation (sunspots shocks) can generate persistent and empirically consistent fluctuations in the unemployment rate and output growth. In order to do so, an approximation of the solution to the dynamic system (1) and (2) is needed. Since we wish to consider the possibility that the economy be located near the points where flip and Hopf bifurcations occur, it might be the case that the true dynamics of the model are too rich to be sufficiently well approximated by a standard linearization procedure. For this reason, we have followed instead the suggestion of Schmitt-Grohé and Uribe (2004) of approximating the solution 


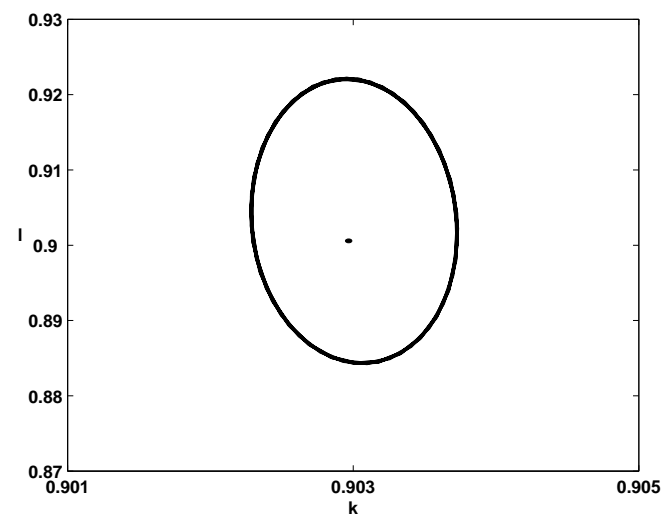

Figure 7: The invariant closed curve in the $(k, l)$ plane near the (supercritical) Hopf bifurcation.

using a second-order expansion of (4). This is likely to better capture the nonlinearities of the model. When the steady state is a sink, sunspot equilibria driven by self-fulfilling changes in expectations exist, and a second order Taylor expansion of a solution satisfying (4) may be written as

$$
\begin{aligned}
\widehat{k}_{t+1} & \simeq \nabla_{1} \widehat{z}_{t}+\frac{1}{2} \widehat{z}_{t}^{\prime} H_{1}(\bar{z}) \widehat{z}_{t} \\
\widehat{l}_{t+1} & \simeq \nabla_{2} \widehat{z}_{t}+\frac{1}{2} \widehat{z}_{t}^{\prime} H_{2}(\bar{z}) \widehat{z}_{t}+e_{t+1}
\end{aligned}
$$

where $\widehat{z}_{t} \equiv\left(\widehat{k}_{t}, \widehat{l}_{t}\right)$ is the vector of endogenous variables expressed in percentage deviations from the steady-state, $e_{t+1}$ is a sunspot shock of bounded support with variance $\gamma, \nabla_{i}(\bar{z})$ is the gradient of the $i^{t h}$ component of $h(),. i=1,2$, evaluated at the steady-state (or, equivalently, the $i^{\text {th }}$ raw of the Jacobian matrix of $h($.$\left.) evaluated at \bar{z}\right)$ and $H_{i}$ is the Hessian matrix of $h($.$) relative to variable i=1,2$ (or, equivalently, the Jacobian matrix of $\left.\nabla_{i}().\right)$ evaluated at $\bar{z}$.

\subsection{Calibration and estimation procedure}

In order to simulate the model, a specific functional form for the production function is required. We consider a CES production function with constant returns to scale, i.e., 
$F\left(k_{t}, l_{t}\right)=A l_{t} f\left(\frac{k_{t}}{l_{t}}\right)=A l_{t}\left[\varphi\left(\frac{k_{t}}{l_{t}}\right)^{\frac{\sigma-1}{\sigma}}+(1-\varphi)\right]^{\frac{\sigma}{\sigma-1}}$ where $0<\varphi<1, \sigma>0$ is the constant elasticity of substitution between inputs, and $A>0$ is a scale parameter. A sensible parametrization for the structural parameters is also needed. The model contains, besides the scale parameter $A$, six other parameters: $\beta, \delta, \sigma, \alpha, b$ and $\varphi$. Our general strategy is to partition these parameters into two groups: those for which there exists relatively common and rather noncontroversial estimates in the literature or for which we can match balanced growth path values with observed averages, and those for which such estimates are not available or are more controversial. The first set of parameters is calibrated, while the second set is estimated so as to minimize a measure of the distance between some preselected moments characterizing our data set and their model-implied counterparts.

The first set of parameters is $\gamma_{1}=(\beta, \delta, b, \varphi)$. As we define the time period to be a quarter, we set $\beta=1.03^{-0.25}$, which implies a steady state annualized real interest rate of 3 percent. We set $\delta=0.025$, which implies an annual depreciation rate on capital of 10 percent. We calibrate the real amount of unemployment compensation $b$ and the (unobserved) technological parameter $\varphi$ so as to match the long-run level of unemployment in France over the period 1982:1 to 2006:4, $u=9.7 \%$, and the long-run labor share of output, $s_{L}=0.6 .^{13}$ Remark that in our model the labor share also represents the fraction of national income that accrues to liquidity constrained consumers, i.e. agents who consume their current income. Extending the seminal analysis of Campbell and Mankiw (1989), this fraction has been estimated in several works, for different countries. ${ }^{14}$ Interestingly, the value obtained for France by Cecchetti et al. (2006) is 0.594, in accordance with our model.

The second set of parameters includes the firms' bargaining power $\alpha$ and the elasticity of substitution between capital and labor $\sigma, \gamma_{2}=(\alpha, \sigma)$. As these parameters are hardly observed, and since they are dramatically important for the dynamic configurations of the model, we estimate them. Following Rotemberg and Woodford (1997), Christiano et al. (2005) and others, these parameters are estimated to match as closely as possible

\footnotetext{
${ }^{13}$ This calibration implies a gross replacement ratio $b / w$ of 0.35 , in accordance with the corresponding value of 0.38 estimated for France (see Cahuc and Zylberberg, 2004).

${ }^{14}$ See among others Campbell and Mankiw (1991), Japelli and Pagano (1989) and Cecchetti et al. (2006).
} 
a preselected set of empirical moments using a Minimum Distance Estimation (MDE) procedure. To be more precise, let $\Psi_{T}^{e}$ be a set of empirical moments characterizing our data set of length $T$, and let $\Psi\left(\gamma_{2}\right)$ be the mapping from the (non calibrated) structural parameters to the corresponding theoretical set of moments. The Minimum Distance Estimator of $\gamma_{2}$, denoted $\widehat{\gamma}_{2}$, is given by

$$
\widehat{\gamma}_{2}=\underset{\gamma_{2} \in \Gamma}{\arg \min }\left(\Psi_{T}^{e}-\Psi\left(\gamma_{2}\right)\right)^{\prime} W\left(\Psi_{T}^{e}-\Psi\left(\gamma_{2}\right)\right)
$$

where $W$ is a positive definite weighting matrix.

A problem that may arise in practice is that, given the relatively small number of observations in our data set $(T=100)$, the model-generated sample equivalent of $\Psi_{T}^{e}$ may be quite different from the theoretical one, $\Psi\left(\gamma_{2}\right)$. For this reason, we relied instead on a standard Method of Simulated Moments, where a short sample equivalent of $\Psi\left(\gamma_{2}\right)$, denoted $\widehat{\Psi}_{T}\left(\gamma_{2}\right)$, was obtained by repeatedly generating from the model artificial data sets of length $T$ and then averaging the sample estimates. These repeated simulations were also used to compute an estimate $\widehat{\Sigma}$ of the variance-covariance matrix of $\widehat{\Psi}_{T}\left(\gamma_{2}\right)$, which served as a basis for the confidence bounds below. Following Christiano et al. (2005), we chose as weighting matrix a diagonal matrix containing along the diagonal the inverse of the sample variances of $\widehat{\Psi}_{T}\left(\gamma_{2}\right)$, i.e. the inverse of the diagonal elements of $\widehat{\Sigma}$. With this choice, the vector or parameters $\gamma_{2}$ is chosen so that the empirical moments $\Psi_{T}^{e}$ lie as much as possible in these confidence bounds.

Finally, some discussion is required about the set of moments that we aimed to match. As the main issue of our paper is on unemployment persistence, and persistence in general, we have chosen to match the two statistical measures which emphasize most strongly this dimension. Namely, we have chosen to match the autocorrelation functions (ACFs) of the (HP-filtered) unemployment rate and of output growth of the French economy. In addition, a choice had to be made about the number of lags in the ACFs to consider. As the ACF function of output growth essentially vanishes after five lags, we chose as a benchmark to retain the first five lags of these autocorrelation functions. Results were not substantially altered, however, when we experimented with different numbers of lags. 
Table $\frac{4 \text { : Estimated parameters values }}{\widehat{\widehat{\alpha}} \widehat{\widehat{\sigma}}}$

$0.5218 \quad 0.7697$

$(0.03) \quad(0.05)$

\subsection{Estimation results}

The estimated vector of parameters was obtained based on the previously described minimization procedure using 500 simulations of data sets including $T=100$ observations. Table 4 reports the estimated values for $\widehat{\gamma}_{2}=(\widehat{\alpha}, \widehat{\sigma})$, while Figure 8 reports the empirical autocorrelation functions together with their theoretical (sample average) counterparts. The match appears to be excellent, with the empirical and theoretical autocorrelation functions being very close from each other and the two empirical autocorrelation functions lying entirely within the simulated 95\% confidence bounds. Thus, the simulated version of the model is able to replicate the large amount of persistence in unemployment fluctuations and output growth which characterizes the French and many European economies.

Note that these strongly persistent effects of shocks occur while, by definition, sunspot shocks are restricted to be serially-uncorrelated stochastic processes. There is therefore no doubt that this large amount of persistence is endogenous to the model, resulting entirely from internal propagation mechanisms and not from an exogenous source of persistence introduced through the stochastic driving processes. This is an important point, because Cogley and Nason (1995) strongly emphasized the difficulties of many DSGE models in replicating the autocorrelation function of output growth without introducing an exogenous source of persistence. Schmitt-Grohé (2000) stressed the same difficulties for the available generation of sunspot-driven models.

Another simple way of emphasizing this strong endogenous persistence is to locate the estimated parameters in Figure 6 and observe that they fall very close to the locus of Hopf bifurcations in the $(\alpha, \sigma)$ plane. Indeed, persistence in a dynamic model is obtained when the roots (eigenvalues) of its characteristic polynomial have their modulus close to one. As our (reduced) dynamic system is two-dimensional, it is clear that large endogenous persistence will prevail when parameters are in the neighborhood of a Hopf bifurcation, since in this case the two eigenvalues are complex conjugates close to the unit circle. 

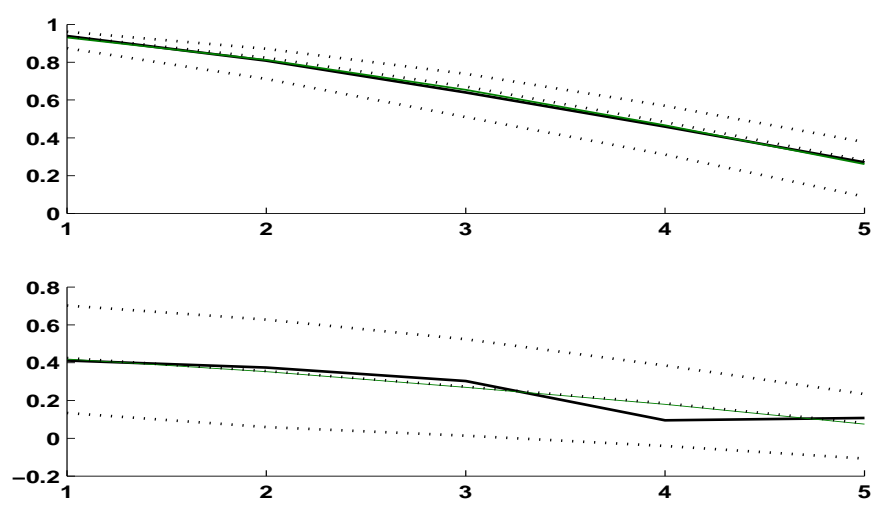

Figure 8: Empirical and model-implied autocorrelation functions for hp-filtered unemployment (upper graph) and output growth (lower graph). Dotted lines are confidence bounds.

The important point to emphasize is that the Hopf bifurcation occurs for standard and realistic values of the structural parameters. For example, the estimated value for the elasticity of substitution between capital and labor, $\widehat{\sigma}=0.77$, is close to the value of $\sigma=0.7$ used in Pissarides (1998), Maffezzoli (2001), Chéron and Langot (2004), and others. Similarly, the estimated value for the firms bargaining power, $\widehat{\alpha}=0.52$, is close to the standard value of 0.5 usually considered in the Labor Economics literature. It is also close to the value of 0.6 considered in the comparable DSGE literature with unemployment (see, e.g., Andolfatto (1996) and Chéron and Langot, 2004).

This aspect is, we believe, one important contribution of our model with respect to the literature. Indeed, in many papers, bifurcations and indeterminacy can only occur under rather controversial features such as, e.g., strong enough increasing returns to scale in production (Benhabib and Farmer (1994), Farmer and Guo, 1994), ${ }^{15}$ strongly distortive taxation (Guo and Lansing, 1998), a large share of public spending in production (SchmittGrohé and Uribe, 1997), etc. In our model, by contrast, indeterminacy typically prevails under constant returns to scale and an arbitrary (positive) size of public redistribution. ${ }^{16}$

\footnotetext{
${ }^{15}$ Some papers have tried to overcome this difficulty. A non-exhaustive list of papers includes the two-sector model of Benhabib and Farmer (1996), Wen's (1998) model of variable capital utilization rate, and Jaimovich (2008), who analyses the influence of income effects on indeterminacy.

${ }^{16}$ See Dufourt et al. (2008) for an explanation of why indeterminacy occurs independently of the level of unemployment benefits. On the contrary, in Grandmont (2008) indeterminacy requires a minimum level of
} 
Furthermore, provided that the unions' bargaining power is strong enough, flip and Hopf bifurcations both arise for plausible values of the capital-labor elasticity of substitution.

Note also that the model offers an explanation for the high persistence of unemployment fluctuations, highlighted in section 2 , which is relatively new in the literature. To account for this feature, early theoretical explanations have typically relied on hysteresis models with multiple equilibria, such as the canonical "insiders-outsiders"model of Blanchard and Summers (1987), in which the preferences of unions are implicitly assumed to exclude previously fired or unemployed workers. In this tradition of models, persistent unemployment fluctuations occur because transitory shocks affect permanently the long-run (or natural) rate of unemployment. This may explain both persistence and the sensibility of unemployment rates to transitory - potentially country specific - shocks, which could account for the heterogeneity across European countries. Although this type of explanations was initially very attractive, receiving a great deal of attention in the literature, its impact was later mitigated due to the lack of definitive supporting empirical evidence. In fact, in several countries, statistical tests led to a rejection of a unit root in unemployment series (especially for recent decades), suggesting a very persistent, but in the end stable, natural rate of unemployment. ${ }^{17}$ The stability of the overall unemployment series for the EU15 since the mid-80s seems to strengthen this conclusion.

More recently, DSGE models in the RBC tradition have also attempted to account for unemployment persistence without giving up the assumption of a stable natural rate of unemployment. For this purpose, various labor markets frictions were considered: frictions in the matching process between workers and firms (Merz (1995) and Andolfatto, 1996), wage bargaining (Maffezzoli (2001) and Chéron and Langot, 2004) and endogenous job destruction (Den Haan et al., 2000). In general, these papers have shown that standard DSGE models with labor market imperfections could reproduce the amount of persistence in unemployment series found in the data provided persistent exogenous shocks (in particular technological innovations) were introduced as driving processes. ${ }^{18}$

unemployment insurance, whereas in Nakajima (2006) less unemployment insurance makes indeterminacy more likely.

${ }^{17}$ See for example Evans (1989) for an analysis on US data.

${ }^{18}$ However, as stressed by Shimer (2005), these models tend to underestimate unemployment fluctuations (volatility). A possible solution for this puzzle in RBC models, where exogenous shocks on fundamentals are the source of cycles, is to introduce a mechanism able to generate higher wage rigidity than the traditional Nash wage bargaining set up. On this discussion see also Hall (2005), Pissarides 
Two important features differentiate our model from these previous works. First, in contrast to the hysteresis literature, our model does not rely on the existence of a unit root in the unemployment series to generate the strong persistence typically observed in European countries. As such, our model is consistent with a stable unemployment rate in the long run, which seems to be in accordance with the evolution of the EU15 unemployment rate since the mid 1980s. Second, with respect to the traditional DSGE literature, our model does not rely on exogenous shocks on productivity to account for unemployment persistence and cross-country heterogeneity in European unemployment rates. Rather, autonomous changes in expected inflation are the trigger mechanism. Because such expectations are very heterogenous (see section 2), the model can conciliate the diversity of cyclical unemployment fluctuations within the European Union with the (common) strong persistence.

To the best of our knowledge, this model is the first to explain persistent unemployment fluctuations with self-fulfilling changes in expected inflation. However, by no means do we want to claim that these shocks are the only source of unemployment variations. In fact, the above analysis suggests that long-lasting unemployment fluctuations would result in this model from any kind of shocks (whether on fundamentals or on expectations) and whatever the degree of persistence of these shocks. Using white noise expected inflation shocks is simply the most eloquent way to emphasize this dimension, in addition to having significant empirical support (see section 2.2). The next section illustrates how other transitory shocks (such as shocks on unions bargaining power) also lead to rich internal dynamics in the model.

\subsection{Other business cycle features}

The ability of our model to account for the strong persistence in unemployment fluctuations and output growth observed in the data would be undermined if the model failed in replicating other standard stylized facts of the business cycle. For this reason, we now turn to the evaluation of the model with respect to these other features. This is important, because Cogley and Nason (1995) emphasized the difficulties of many DSGE models in accounting for important empirical regularities, concerning in particular: (i) the positive (2007) and Costain and Reiter (2008). 
autocorrelation of output growth found in many countries, and (ii) the hump-shaped response of output to transitory shocks. In addition, models driven by demand shocks and, in particular, standard sunspot-driven models (as emphasized by Schmitt-Grohé, 2000), have a third caveat: their inability to account for (iii) the positive comovements of consumption, investment, output and hours worked in response to transitory shocks, unless incredibly high increasing returns to scale are assumed.

In a recent paper, Benhabib and Wen (2004) showed that many of these problems could be alleviated by considering a version of Wen's (1998) model with variable capital utilization rate and moderate increasing returns to scale, where sunspot shocks alone or combined with other demand shocks are considered. Specifically they show that, for a realistic calibration (which implies that the model is locally indeterminate and near a flip bifurcation), their model is able to replicate the three stylized facts that previous models driven by demand shocks were unable to account for. The key argument is that with indeterminacy, the internal propagation mechanisms are strong enough to translate (serially correlated) exogenous demand shocks (to preferences or to government spending) into persistent, hump-shaped, and positively correlated comovements in output, consumption and hours worked. Therefore, a strong case for models with local indeterminacy and bifurcations could be made.

Since we view the Benhabib and Wen model as the most successful one among the current generation of sunspot-driven DSGE models, it is important to relate our results to those in that paper. Below we argue that, with respect to the three stylized facts mentioned above, ${ }^{19}$ our model performs as well as the Benhabib and Wen model and, in certain aspects, we believe it even improves some predictions. We explain why by considering successively each of the three stylized facts.

Persistence in output growth The fact that our model can replicate the persistence of output growth is obvious from Figure 8. What differentiates our results to those of Benhabib and Wen (2004) is that we obtain sufficiently strong persistence in output

\footnotetext{
${ }^{19}$ We do not refer to the positive correlation between the "forecastable movements" in output, consumption and hours emphasized by Rotemberg and Woodford (1996), because these measures mostly make sense in the presence of permanent technological shocks implying a unit root in output. It should be clear however that these measures of the business cycle, and those here addressed, share many similar features.
} 
growth even if expected inflation shocks, which are by definition serially-uncorrelated, are the only source of disturbances in the economy. By contrast, in Benhabib and Wen (2004), a combination of sunspot shocks with another source of (positively autocorrelated) fundamental disturbances is required to obtain enough persistence. Indeed, in the version of their model submitted to sunspot shocks only, they report a first-order autocorrelation coefficient of output growth of only 0.10. This compares to a value of 0.39 for the US and a value of 0.41 for France. By comparison, our estimated model with sunspot shocks provides a coefficient of 0.40 , much closer to the empirical estimates. This shows that our amplification mechanisms are strong enough to translate purely white-noise sunspot shocks into persistent movements in unemployment and output consistent with empirical evidence.

\section{Positive comovements of output, hours, consumption and investment to tran-} sitory/demand shocks To analyze the model's predictions in this dimension, it is useful to look at Figure (9a), which displays the theoretical impulse response functions (IRFs) of the main variables to a sunspot shock obtained with the second-order approximation of the dynamic system. As expected, we can observe that sunspot shocks generate highly persistent periods of booms and recessions affecting simultaneously all the variables, with deviations from the steady state that are still significant even after 20 quarters. More importantly, the figure shows that in the aftermath of a positive sunspot shock, output, employment, total consumption, investment and the capital stock all increase simultaneously for several periods, then decrease towards negative values for a few periods and eventually revert back slowly to the initial steady state. Thus, as in Benhabib and Wen (2004), the model is able to generate periods of booms and recessions (boom-bust cycles) resulting from autonomous changes in expectations. There are however differences in terms of mechanisms, since we obtain positive comovements in the components of output without relying on increasing returns to scale. In our model, the traditional crowding-out effect of demand shocks on private consumption is attenuated because liquidity-constrained workers cannot smooth consumption across time and end-up consuming their current income. This explains why consumption remains positively correlated with output in response to a sunspot shock, in contrast to traditional sunspot-driven 


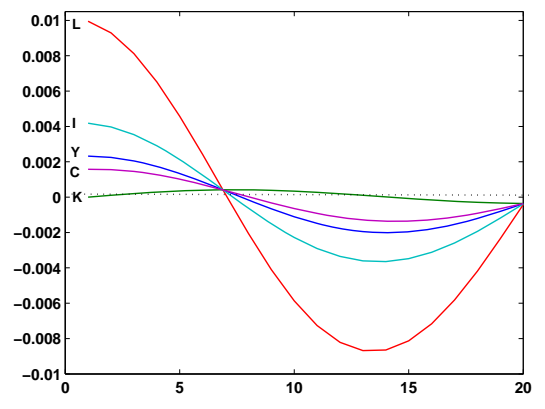

(a) Expected inflation shock

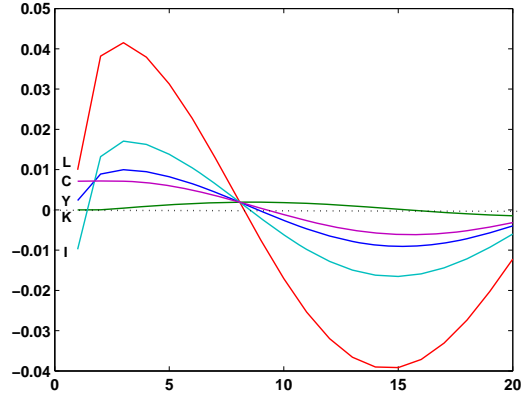

(b) Bargaining power shock

Figure 9: Impulse Response Functions with second-order approximation

models. ${ }^{20}$

Hump-shaped response of output to transitory shocks Figure 9(a) also clearly illustrates that the economy's response to a sunspot shock is non-monotonous. From a technical point of view, the fact that, near a Hopf bifurcation, the two eigenvalues of the Jacobian matrix are complex conjugates with modulus close to one explains the nature of this non-monotonous convergence to the steady-state. In spite of this, the impulse response function of output to a sunspot shock does not display the typical hump following transitory shocks characterizing many real economies. Note that all the models considered in Schmitt-Grohé (2000) were unable to account for this feature, and this also includes the Benhabib and Wen model when sunspot shocks alone are considered. ${ }^{21}$ Yet, as in this latter paper, we expect that the endogenous persistence mechanisms emphasized above are strong enough to obtain a hump-shaped response of output to transitory demand shocks that are slightly positively autocorrelated. To verify this conjecture, we experimented a version of the model where unions' bargaining power is variable and subject to stochastic shocks. For example, we can assume that firms' bargaining power follows a simple AR(1)

\footnotetext{
${ }^{20}$ This specific issue is discussed in detail in the survey by Benhabib and Farmer (1999). In standard models, a sunspot shock that increases employment also decreases the real wage - and thus consumption - unless high increasing returns are considered. One solution to mitigate this problem is to combine smaller increasing returns to scale with variable capacity utilization (as in Benhabib and Wen, 2004) or with endogenous countercyclical markups (as in Dos Santos Ferreira and Dufourt, 2006).

${ }^{21}$ In a recent paper, Wang and Wen (2008) obtain a hump-shaped response of output to sunspot shocks by considering serially-correlated sunspot shocks in a model with global indeterminacy.
} 
process $\ln \left(\alpha_{t} / \alpha\right)=\rho \ln \left(\alpha_{t-1} / \alpha\right)+\varepsilon_{\alpha, t}$, where $\varepsilon_{\alpha, t}$ is a white-noise shock and $\rho$ a persistence parameter, and analyze the effects of an increase in unions' bargaining power. Because there is local indeterminacy of the steady-state, there exist multiple admissible trajectories following this shock, depending on how expected inflation (which is a free variable) reacts to fundamental disturbances. However, these multiple trajectories mostly differ in terms of the contemporaneous responses of the endogenous variables, and not so much in terms of the future effects (for periods $t+1$ and after). Figure 9 (b) displays a typical impulse response function following a $1 \%$ shock on unions' bargaining power when the autoregressive coefficient $\rho$ is set to 0.2 . In spite of the low persistence in the exogenous stochastic process, the model does generate the hump-shaped and persistent response of output which is typical of the data. This is true although we assumed a much lower degree of persistence in the exogenous stochastic process (as measured by the parameter $\rho$ ) than in Benhabib and Wen (2004). ${ }^{22}$ This confirms, as emphasized earlier, the presence of very strong amplification mechanisms internal to the model.

Other standard stylized facts Finally, we discuss briefly the performance of our model with respect to the more standard business cycle statistics emphasized in the Real Business Cycle literature. Table 5 summarizes the results in terms of cross-correlations, relative standard deviations and autocorrelations between the (HP-filtered) cyclical components of the variables when the model is submitted to i.i.d. sunspot disturbances of arbitrary size. $^{23}$

In conformity with the IRF analysis, the statistics confirm that the model generates positive correlations between output, aggregate consumption, employment and investment. Although the model overstates considerably the volatility of the employment rate, this does not seem to be a strong limitation of the model. Introducing other shocks or adding an intensive margin for labor (effort, as in Grandmont, 2008) or for capital (variable utilization rate, as in Benhabib and Wen, 2004) are both likely to improve the model's performance in this dimension.

\footnotetext{
${ }^{22}$ The authors indicate that large enough persistence parameter values for government spending and preferences shocks are necessary in their model to account for the business cycle facts. In their experiment, they calibrate the persistence parameter to $\rho=0.9$.

${ }^{23}$ Of course, the size of the sunspots must be small enough to ensure that the dynamics remain in the basin of attraction of the steady state.
} 
Table 5 - Business Cycle Statistics

\begin{tabular}{|c|c|c|}
\hline \multirow[b]{2}{*}{ Variable (x) } & \multicolumn{2}{|c|}{ Relative S.D. with output $\sigma_{x} / \sigma_{y}$} \\
\hline & $\begin{array}{ll}c & i\end{array}$ & $l$ \\
\hline Data & $0.56 \quad 3.14$ & 0.93 \\
\hline \multirow[t]{2}{*}{ Model } & 1.80 & 3.89 \\
\hline & \multicolumn{2}{|c|}{ Correlations with output $\operatorname{Corr}(y, x)$} \\
\hline Variable $(\mathrm{x})$ & $c \quad i$ & $l$ \\
\hline Data & 0.74 & 0.78 \\
\hline \multirow[t]{3}{*}{ Model } & $0.99 \quad 0.99$ & 0.99 \\
\hline & \multicolumn{2}{|c|}{ AR coeffs. on output $\rho_{i}=\operatorname{corr}\left(y_{t}, y_{t-i}\right)$} \\
\hline & $\rho_{1} \quad \rho_{2}$ & $\rho_{3}$ \\
\hline Data & 0.87 & 0.46 \\
\hline Model & 0.91 & 0.60 \\
\hline
\end{tabular}

On the other hand, an interesting feature of the model is that it does not generate an excessive smoothness of consumption relatively to output, which is a typical weakness of standard RBC models with complete markets and risk-averse consumers. Indeed, in such models, households tend to smooth out consumption fluctuations through savings in response to exogenous disturbances. In contrast, the explanation for this successful feature in our model is that, at equilibrium, financially constrained workers choose to spend all their available income in current consumption. As total income of workers is procyclical, so is workers consumption, explaining the procyclicality of consumption and its strong sensitivity to current production. Note in particular how the business cycle properties of consumption change radically according to whether agents are financially constrained or not. As Table 6 shows, in the case of workers, the sensitivity of consumption to current income is strong, with a correlation coefficient near unity and a relative standard deviation of 0.77 . On the contrary, consumption of capitalists seems much less related to variations in current income: the contemporaneous correlation with output drops to 0.31 , and consumption of capitalists is 0.17 percent as volatile as output. As workers' consumption accounts for a large proportion of total consumption, its cyclical properties clearly dominate at the aggregate level. Hence, the excess sensitivity of consumption to current income puzzle identified in the empirical literature is accounted for by the 
Table 6 - Cyclical properties of consumption relative to output

\begin{tabular}{cclll}
\multicolumn{2}{c}{$\sigma_{c} / \sigma_{y}$} & & \multicolumn{2}{c}{$\operatorname{Corr}(y, c)$} \\
\cline { 1 - 1 } \cline { 5 - 6 }$c^{w}$ & $c^{c}$ & & $c^{w}$ & $c^{c}$ \\
0.77 & 0.17 & & 1 & 0.31 \\
\hline \hline
\end{tabular}

difficulty for workers to smooth consumption variations in the presence of liquidity constraints. Note that this view of the problem is supported by both the theoretical and the empirical literature (see e.g. Japelli and Pagano (1989) and Cecchetti et al., 2006). For example, Cecchetti et al. (2006), using data for several countries, find that the volatility of consumption decreases when household liquidity constraints are relaxed.

\section{Concluding remarks}

Following the literature on endogenous fluctuations and "sunspots equilibria", that revives the Keynesian idea of "animal spirits", we introduced i.i.d. shocks on expectations in a model where expected inflation changes are a crucial determinant of the current levels of activity and unemployment. We find that, in this set up and for reasonable values of the parameters, self fulfilling volatile expectations of future inflation are able to simultaneously account for the cross-country heterogeneity and strong persistence in European unemployment rates. In addition, the model replicates several stylized facts that standard RBC and sunspot-driven models hardly accounted for. This includes the persistent autocorrelation functions of unemployment and output growth, the positive comovements of consumption, output and hours worked, and the large volatility of consumption relatively to output.

Finally let us remark that our model, besides being successful in reproducing the main empirical regularities displayed by macroeconomic variables, also brings together two modern approaches to the study of business cycles with a clear Keynesian flavour: endogenous fluctuations driven by self-fulfilling expectations and the New Keynesian Phillips Curve literature. 


\section{References}

[1] Andolfatto, David. 1996. "Business Cycles and Labor-Market Search." American Economic Review, 86(1): 112-132.

[2] Azariadis, Costas. 1981. "Self-fulfilling Prophecies." Journal of Economic Theory, 25(3): 380-396.

[3] Azariadis, Costas, and Roger Guesnerie. 1986. "Sunspots and Cycles." Review of Economic Studies, 53(5): 725-737.

[4] Benhabib, Jess, and Roger E. A. Farmer. 1994. "Indeterminacy and Increasing Returns." Journal of Economic Theory, 63(1): 19-41.

[5] Benhabib, Jess, and Roger E. A. Farmer. 1996. "Indeterminacy and SectorSpecific Externalities." Journal of Monetary Economics, 37(3): 421-444

[6] Benhabib, Jess, and Roger E. A. Farmer. 1999. "Indeterminacy and Sunspots in Macroeconomics." In Handbook of Macroeconomics, ed. John B. Taylor and Michael Woodford, 387-448. Amsterdam, North-Holland: Elsevier.

[7] Benhabib, Jess, and Yi Wen. 2004. "Indeterminacy, Aggregate Demand and the Real Business Cycle." Journal of Monetary Economics, 51(3): 503-530.

[8] Blanchard, Olivier. 2006. "European Unemployment: The Evolution of Facts and Ideas." Economic Policy, 21: 5-59.

[9] Blanchard, Olivier, and Lawrence H. Summers. 1987. "Hysteresis in Unemployment." European Economic Review, 31(1): 288-295.

[10] Cahuc, Pierre, and André Zylberberg. 2004. Labor Economics. Cambride, MA: MIT Press.

[11] Campbell, John Y., and Gregory N. Mankiw. 1989. "Consumption, Income and Interest Rates: Reinterpreting the Time Series Evidence." In NBER macroeconomics annual, ed. Olivier Blanchard and Stanley Fisher, Cambridge, MA: MIT press. 
[12] Campbell, John Y. and Gregory N. Mankiw. 1991. "The Response of Consumption to Income: A Cross-country Investigation." European Economic Review, 35(4): 723-756.

[13] Cass, David, and Karl Shell. 1983. "Do Sunspots Matter?" Journal of Political Economy, 91(2): 193-227.

[14] Cazzavillan, Guido, Teresa Lloyd-Braga and Patrick Pintus. 1998. "Multiple Steady States and Endogenous Fluctuations with Increasing Returns to Scale in Production." Journal of Economic Theory, 80(1): 60-107.

[15] Cecchetti, Stephen G., Alfonso Flores-Lagunes, and Stefan Krause. 2006. "Financial Development, Consumption Smoothing, and the Reduced Volatility of Real Growth.", AEA 2007 Conference Papers.

[16] Chéron, Arnaud, and François Langot. 2004. "Labor Market Search and Real Business Cycles: Reconciling Nash Bargaining with the Real Wage Dynamics." Review of Economic Dynamics, 7(2): 476-493.

[17] Christiano, Lawrence J., Martin Eichenbaum, and Charles L. Evans. 2005. "Nominal Rigidities and the Dynamic Effects of a Shock to Monetary Policy." Journal of Political Economy, 113(1): 1-45.

[18] Cogley, Timothy, and James M. Nason. 1995. "Output Dynamics in RealBusiness-Cycle Models." American Economic Review, 85(3): 492-511.

[19] Costain, James S., and Michael Reiter. 2008. "Business Cycles, Unemployment Insurance, and the Calibration of Matching Models." Journal of Economic Dynamics and Control, 32(4): 1120-1155.

[20] Den Haan, Wouter J., Gary Ramey, and Joel Watson. 2000. "Job Destruction and Propagation of Shocks." American Economic Review, 90(3): 482-498.

[21] Dos Santos Ferreira, Rodolphe, and Frédéric Dufourt. 2006. "Free Entry and Business Cycles Under the Influence of Animal Spirits." Journal of Monetary Economics, 53(2): 311-328. 
[22] Dufourt, Frédéric, Teresa Lloyd-Braga, and Leonor Modesto. 2005. "Indeterminacy and Unemployment Fluctuations with Constant Returns to Scale in Production." CEPR Discussion Papers 4874.

[23] Dufourt, Frédéric, Teresa Lloyd-Braga, and Leonor Modesto. 2008. "Indeterminacy, Bifurcations and Unemployment Fluctuations." Macroeconomic Dynamics, $12(\mathrm{~S} 1)$ : 75-89.

[24] Evans, George W. 1989. "Output and Unemployment Dynamics in the United States: 1950-1985." Journal of Applied Econometrics, 4(3): 213-237.

[25] Farmer, Roger E. A, and Jan-Ting Guo. 1994. "Real Business Cycles and the Animal Spirits Hypothesis." Journal of Economic Theory, 63(1): 42-72.

[26] Farmer, Roger E. A., and Michael Woodford. 1984. "Self-fulfilling Prophecies and the Business Cycle." CARESS Paper 8412, Univ. of Pennsylvania.

[27] Farmer, Roger E. A., and Michael Woodford. 1997. "Self-fulfilling Prophecies and the Business Cycle." Macroeconomic Dynamics, 1(4): 740-769.

[28] Friedman, Milton. 1968. "The Role of Monetary Policy." American Economic Review, 58(1): 1-17.

[29] Galí, Jordi, and Mark L. Gertler. 1999. "Inflation Dynamics: A Structural Econometric Analysis." Journal of Monetary Economics, 44(2): 195-222.

[30] Grandmont, Jean-Michel. 1985. "On Endogenous Competitive Business Cycles." Econometrica, 53(5): 995-1045.

[31] Grandmont, Jean-Michel. 2008. "Negishi-Solow Efficiency Wages, Unemployment Insurance and Dynamic Deterministic Indeterminacy." International Journal of Economic Theory, 4: 247-292.

[32] Grandmont, Jean-Michel, Patrick Pintus, and Robin de Vilder. 1998. "Capital-Labour Substitution and Competitive Nonlinear Endogenous Business Cycles." Journal of Economic Theory, 80(1): 14-59. 
[33] Guo, Jang-Ting, and Kevin J. Lansing. 1998. "Indeterminacy and Stabilization Policy." Journal of Economic Theory, 82(2): 481-490.

[34] Hall, Robert E. 2005 "Employment Fluctuations with Equilibrium Wage Stickiness." American Economic Review, 95(1): 50-65.

[35] Jaimovich, Nir. 2008. "Income Effects and Indeterminacy in a Calibrated One Sector Growth Model." Journal of Economic Theory, 143(1): 610-623.

[36] Japelli, Tulio, and Marco Pagano. 1989. "Consumption and Capital Market Imperfections: An International Comparison." American Economic Review, 79(5): 1088-1105.

[37] Maffezzoli, Marco. 2001. "Non-Walrasian Labor Markets and Real Business Cycles." Review of Economic Dynamics, 4(4): 860-892.

[38] Merz, Monika. 1995. "Search in the Labor Market and the Real Business Cycle." Journal of Monetary Economics, 36(2): 269-300.

[39] Mortensen, Dale T., and Christopher A. Pissarides. 1994. "Job Creation and Job Destruction in the Theory of Unemployment." Review of Economic Studies, 61(3): 397-415.

[40] Nakajima, Tomoyuki. 2006. "Unemployment and Indeterminacy." Journal of Economic Theory, 126(1): 314-327.

[41] Pissarides, Christopher A. 1998. "The Impact of Employment Tax Cuts on Unemployment and Wages; The Role of Unemployment Benefits and Tax Structure." European Economic Review, 42(1): 155-183.

[42] Pissarides, Christopher A. 2007. "The Unemployment Volatility Puzzle: is Wage Stickiness the Answer?", LSE Research Oline, http://eprints.lse.ac.uk/3785/.

[43] Phelps, Edmund S. 1967. "Phillips Curves, Expectations of Inflation, and Optimal Unemployment over Time." Economica, 34: 254-281

[44] Phelps, Edmund S. 1968. "Money-Wage Dynamics and Labor Market Equilibrium." Journal of Political Economy, 76(4): 678-711. 
[45] Rotemberg, Julio, and Michael Woodford. 1996. "Real-Business-Cycle Models and the Forecastable Movements in Output, Hours and Consumption." American Economic Review, 86(1): 71-89.

[46] Rotemberg, Julio, and Michael Woodford. 1997. "An Optimization-based Econometric Framework for the Evaluation of Monetary Policy." in NBER Macroeconomics Annual 1997, ed. Ben Bernanke and Michael Woodford, Cambridge: MIT Press.

[47] Schmitt-Grohé, Stephanie. 2000. "Endogenous Business Cycles and the Dynamics of Output, Hours and Consumption." American Economic Review, 90(5): 1136-1159.

[48] Schmitt-Grohé, Stephanie, and Martin Uribe. 1997. "Balanced-Budget Rules, Distortionary Taxes, and Aggregate Instability." Journal of Political Economy, 105(5): 976-1000.

[49] Schmitt-Grohé, Stephanie, and Martin Uribe. 2004. "Solving Dynamic General Equilibrium Models Using a Second-Order Approximation to the Policy Function." Journal of Economic Dynamics and Control, 28(4): 755-775.

[50] Shell, Karl. 1977. "Monnaie et Allocation Intertemporelle." Séminaire d'Econométrie Roy-Malinvaud, CNRS, Paris.

[51] Shimer, Robert. 2005. "The Cyclical Behavior of Equilibrium Unemployment and Vacancies." American Economic Review, 95(1): 25-49.

[52] Wang, Pengfei, and Yi Wen. 2008. "Imperfect Competition and Indeterminacy of Aggregate Output." Journal of Economic Theory, 143(1): 519-40.

[53] Wen, Yi. 1998. "Capacity Utilization under Increasing Returns to Scale." Journal of Economic Theory, 81(1): 7-36.

[54] Woodford, Michael. 1986. "Stationary Sunspot Equilibria in a Finance Constrained Economy." Journal of Economic Theory, 40(1): 128-137. 


\section{Appendix A}

We provide in this appendix a brief description of the problems solved by capitalists, workers, unions and firms.

Capitalists maximize $E \sum_{t=0}^{\infty} \beta^{t} \log c_{t}^{c}$, where $\beta \in(0,1)$ is the discount factor and $c_{t}^{c}$ is consumption in period $t$, subject to the constraint $p_{t} c_{t}^{c}+p_{t} k_{t+1}^{c}+m_{t+1}^{c}=p_{t} R_{t} k_{t}^{c}+m_{t}^{c}$, where $p_{t}$ is the price of output, $k_{t+1}^{c}$ and $m_{t+1}^{c}$ are, respectively, the capital stock and money holdings at the outset of period $t+1, R_{t}=\left(r_{t}+1-\delta\right)$ is the real gross rate of return on capital, $r_{t}$ is the real rental rate of capital, and $0 \leq \delta \leq 1$ is the capital depreciation rate. Under the condition $R_{t+1}>E_{t}\left\{p_{t} / p_{t+1}\right\}$, the solution of the capitalists' problem is (see Woodford, 1986):

$$
\begin{aligned}
m_{t+1}^{c} & =0 \\
c_{t}^{c} & =(1-\beta) R_{t} k_{t}^{c} \\
k_{t+1}^{c} & =\beta R_{t} k_{t}^{c}
\end{aligned}
$$

In addition the following transversality condition must be verified:

$$
\lim _{t \rightarrow \infty} \underset{0}{E}\left\{\beta^{t} \frac{1}{c_{t}^{c}}\left(k_{t+1}^{c}+\frac{m_{t+1}^{c}}{p_{t}}\right)\right\}=0
$$

At any date, workers can be either employed (state $e$, supplying inelastically one unit of labor) or unemployed (state $u$ ). Whether employed or not, earnings are paid with a one-period delay. It is also assumed that when deciding how much to consume in $t$, a worker does not know yet whether he will be employed or unemployed during the current period (but he can put a probability distribution over the two states, which consists in period $t$ employment $\left(l_{t}\right)$ and unemployment rates $\left(1-l_{t}\right)$, respectively). Workers maximize $E \sum_{t=0}^{\infty} \gamma^{t} u\left(c_{t}^{i}\right)$, subject to $m_{t+1}^{i}+p_{t} k_{t+1}^{i}=m_{t}+p_{t} y_{t}^{i}+p_{t} R_{t} k_{t}-p_{t} c_{t}^{i}$, where the instantaneous utility $u(c)$ is a concave function, $c_{t}^{i}$ is consumption in $t$ of a worker in state $i \in\{e, u\}, \gamma \in(0, \beta)$ is their discount factor, $m_{t}^{w}$ denotes money held at the beginning of period $t$, and $y_{t}^{i} \in\left\{w_{t-1} / p_{t}-\tau_{t-1}, b\right\}$ represents workers real earnings in period $t$, which are contingent on their employment status in period $t-1$ (real wages net of taxes, $w_{t-1} / p_{t}-\tau_{t-1}$, for those employed, and a constant real unemployment benefit, $b$, for those

unemployed). Additionally they face the borrowing constraint $m_{t+1}^{i} \geq 0$, and $k_{t+1}^{i} \geq 0$ for 
all $t .^{24}$ Denoting by $\lambda_{t}^{i}, v_{t}^{i}$ and $\eta_{t}^{i}$ the Lagrange multipliers associated respectively with these three constraints, the first order conditions for the workers' problem with a positive level of consumption are given by:

$$
\begin{aligned}
u^{\prime}\left(c_{t}^{i}\right) & =p_{t} \lambda_{t}^{i} \\
\lambda_{t}^{i}-v_{t}^{i} & =\gamma E_{t}\left\{l_{t} \lambda_{t+1}^{e}+\left(1-l_{t}\right) \lambda_{t+1}^{u}\right\} \\
p_{t} \lambda_{t}^{i}-\eta_{t}^{i} & =\gamma E_{t}\left\{p_{t+1} R_{t+1}\left[l_{t} \lambda_{t+1}^{e}+\left(1-l_{t}\right) \lambda_{t+1}^{u}\right]\right\}
\end{aligned}
$$

We are looking for conditions under which workers endogenously choose to hold neither capital nor money and to consume their current income $c_{t}^{i}=y_{t}^{i} / p_{t}$ under all possible states (employed or unemployed). This means that we are looking for the sequences of revenues and probability distributions over employment and unemployment that are consistent with $v_{t}^{i}>0$, so that $m_{t+1}=0$, and $\eta_{t}^{i}>0$, so that $k_{t+1}=0$, for all $t=0, \ldots, \infty$ and all $i \in\{e, u\}$. Under the condition $R_{t+1}>E_{t}\left\{p_{t} / p_{t+1}\right\}$, this implies that the following inequality

$$
u^{\prime}\left(c_{t}^{i}\right)>\gamma E_{t}\left\{R_{t+1}\left[l_{t} u^{\prime}\left(c_{t+1}^{e}\right)+\left(1-l_{t}\right) u^{\prime}\left(c_{t+1}^{u}\right)\right]\right\}
$$

must hold for all $i \in\{e, u\}$, and where, for $t=0, \ldots, \infty$, we have $c_{t}^{e}=y_{t}^{e}=\left(w_{t-1} / p_{t}-\tau_{t-1}\right)$ and $c_{t}^{u}=y_{t}^{u}=b .{ }^{25}$ Due to the concavity of $u$ and $y^{e} \geq y^{u}$ (a condition implied by the wage bargaining process), condition (12) is verified at the steady state with $R=1 / \beta>1$ if

$$
\gamma<\beta\left\{u^{\prime}\left(y^{e}\right) /\left[l u^{\prime}\left(y^{e}\right)+(1-l) u^{\prime}\left(y^{u}\right)\right]\right\}
$$

Of course, since the expression between curled brackets is lower than 1 , this condition can only be verified if $\gamma<\beta$, implying that workers are sufficiently more impatient than capitalists. In summary condition (13) implies that, at the steady state and in its neighborhood, capitalists do not hold money and workers do not hold money or capital, their consumption being identical, in every period $t$, to their current income $y_{t}^{i}$.

\footnotetext{
${ }^{24}$ For simplicity of notation, we dropped the superscrit $w$.

${ }^{25}$ For the proof to be fully correct, further conditions on the initial amounts of capital and cash-in-hands of the worker at period $0,\left(k_{0}, m_{0}+p_{0} y_{0}\right)$, have to be introduced to ensure that constraint $(12)$ is satisfied in any period. For simplicity and consistency of notation, we simply assume that $k_{0}=0, m_{0}=0$, and that $y_{0}$ takes either the steady state values $w / p-\tau$ or $b$ with probability $l$ and $(1-l)$ respectively.
} 
Firms wish to maximize the present value of expected profits, given by

$$
\Pi_{t}=m_{t}^{f}+p_{t} A l_{t} f\left(k_{t}, l_{t}\right)-p_{t} r_{t} k_{t}-w_{t-1} l_{t-1}-m_{t+1}^{f}+\psi E_{t} \Pi_{t+1}
$$

where $A l_{t} f\left(k_{t}, l_{t}\right)$ is the constant returns to scale production function, $0<\psi<1$ is a constant discount factor (which is irrelevant at equilibrium) and $m_{t}^{f}$ is money held by firms at the beginning of period $t$. Each period $t$ events follow the following sequence. First, firms pay in cash last period wages using previous money holdings. Then firms rent capital, $k_{t}$, at a given nominal rental rate $p_{t} r_{t}$. Next, wages and employment are negotiated between unions and firms. Then, firms decide the amount of money holdings (since wages must be paid in cash, the constraint $m_{t+1}^{f} \geq w_{t} l_{t}$ must be verified). Finally, production takes place. Given the sequence of events, we have to solve the firm's problem backwards, starting with the money holdings decision. This means that, at this stage, firms choose the level of money holdings that maximize (14) subject to $m_{t+1}^{f} \geq w_{t} l_{t}$, with $m_{t}^{f}$ given and for given values of $k_{t}, w_{t}$ and $l_{t}$. Denoting by $\mu_{t}$ the lagrange multiplier associated with the constraint, the first order condition for this problem is $\mu_{t}=1-\psi$. We therefore see straightforwardly that, for any $\psi \neq 1$, the cash-in-advance constraint is binding: $m_{t+1}^{f}=w_{t} l_{t}$. Therefore, at the preceding stages, the firms' objective becomes $\Pi_{t}=\left(p_{t} A l_{t} f\left(x_{t}\right)-p_{t} r_{t} k_{t}-w_{t} l_{t}\right)+\psi E_{t} \Pi_{t+1}$.

We now proceed with the wage-employment bargain and then with capital decisions. ${ }^{26}$ Unions wish to maximize the sum of discounted consumptions of their representative member $\Omega_{t}=E_{t}\left\{\left[\left(\frac{w_{t}}{p_{t+1}}-\tau_{t}\right) l_{t}+b\left(1-l_{t}\right)\right]+\gamma \Omega_{t+1}\right\}$. Wages and employment are determined through an efficient bargaining procedure. This implies that $l_{t}$ and $w_{t}$ solve the generalized Nash bargaining problem:

$$
\underset{\left(w_{t}, l_{t}\right) \in \Re_{++}^{2}}{\operatorname{Max}}\left(\Pi_{t}-\bar{\Pi}_{t}\right)^{\alpha}\left(\Omega_{t}-\bar{\Omega}_{t}\right)^{(1-\alpha)} \quad \text { s.t. } \quad l_{t} \leq 1
$$

where $0<\alpha \leq 1$ represents the firm's power in the bargain, and $\left(\bar{\Pi}_{t}, \bar{\Omega}_{t}\right)$ are the fallback payoffs of each party if no agreement in period $t$ is reached. ${ }^{27}$ The fallback payoff of a union is given by $\bar{\Omega}_{t}=b+\gamma \Omega_{t+1}$, so that $\Omega_{t}-\bar{\Omega}_{t}=l_{t}\left(\frac{w_{t}}{p_{t+1}}-b-\tau_{t}\right)$. The fallback payoff

\footnotetext{
${ }^{26}$ All workers are unionized and unions are firm-specific, i.e., there is one union per firm and each union represents the same mass of workers, normalized to one.

${ }^{27}$ If negotiations fail, production does not take place and all workers are unemployed.
} 
of the firm at this stage is $\bar{\Pi}_{t}=-p_{t} \rho_{t} k_{t}+\varphi E_{t} \Pi_{t+1}$, so that $\Pi_{t}-\bar{\Pi}_{t}=p_{t} A l_{t} f\left(x_{t}\right)-w_{t} l_{t}$. We assume that the solution $l_{t}$ of problem (15) always satisfies $l_{t}<1$, so that there is unemployment. Hence, the first order conditions are:

$$
\begin{aligned}
\left(b+\tau_{t}\right) E_{t} \pi_{t+1} & =\operatorname{MPL}\left(k_{t}, l_{t}\right) \\
\omega_{t} & \equiv \frac{w_{t}}{p_{t}}=\mu\left(k_{t}, l_{t}\right) \operatorname{MPL}\left(k_{t}, l_{t}\right),
\end{aligned}
$$

where $M P L\left(k_{t}, l_{t}\right) \equiv A\left[f\left(x_{t}\right)-f^{\prime}\left(x_{t}\right) x_{t}\right]$ is the marginal productivity of labor and $\mu\left(k_{t}, l_{t}\right) \equiv$ $\left[f\left(x_{t}\right)-\alpha f^{\prime}\left(x_{t}\right) x_{t}\right] /\left[f\left(x_{t}\right)-f^{\prime}\left(x_{t}\right) x_{t}\right]>1$ is a markup factor.

The firm, anticipating the result of the bargaining process, chooses $k_{t}>0$ to maximize profits, which yields the following first-order condition

$$
r_{t}=\alpha M P K\left(k_{t}, l_{t}\right)
$$

where $\operatorname{MPK}\left(k_{t}, l_{t}\right)=A f^{\prime}\left(x_{t}\right)$ is the marginal productivity of capital.

Finally, money being constant over time, the money market equilibrium requires $\pi_{t+1}=\omega_{t} l_{t} / \omega_{t} l_{t}$. Using this condition, the balanced-budget condition $\tau_{t}=b\left(1-l_{t}\right) / l_{t}$, (16) and (17), we obtain equation (2) in the text. Inserting (18) into (7), and using the definition $R_{t}=\left(r_{t}+1-\delta\right)$, we obtain equation (1). 